\title{
LA ARCHIVÍSTICA EN COLECCIONES FOTOGRÁFICAS
}

\author{
Berenice Hernández Rochin*
}

\section{Resumen}

Este artículo pretende extender una breve introducción sobre las líneas de acción de la archivística como disciplina y medio eficaz para la correcta documentación de ejemplares fotográficos; describe de manera puntual las principales actividades que permiten preservar el testimonio intangible de la fotografía, ofreciendo ejemplos claros y concisos para el establecimiento de pautas para el acceso a la memoria visual depositada en instituciones, museos y colecciones privadas o públicas; y cuyo objetivo es incentivar la formación de quienes aspiran a desarrollar su labor profesional en este campo y prestan sus servicios a la custodia, procesamiento y conservación del material fotográfico útil para el estudio, investigación, recreación o legado.

Palabras clave: archivística, fotografía y documentación.

\section{Abstract}

This article created to extend a concise introduction of the lines of action of archivistic as a discipline and effective system for optimum process of documentation; it describes the main activities that preserve the intangible testimony deposited in institutions, or public museums and private collections. The information content could be used like a guide to formation of all those who aspire to develop their professional work in this field and want to provide their services to the custody, processing and preservation of photographic materials useful for the study, research, recreation or legacy.

* Apoyo al Desarrollo de Archivos y Bibliotecas de México A. C., Coordinación en Conservación de Fuentes Fotográficas. 
Key words: archives, photography, documentation.

\section{Presentación}

El objetivo de este artículo es optimizar la gestión, administración y conservación de los documentos fotográficos a través de la incorporación del fundamento teórico de la archivística en la formación, registro, organización y descripción de fondos y colecciones.

El contenido precisa los conocimientos técnicos, factores y actividades necesarios para el establecimiento de una metodología flexible que facilite el acceso a la información plasmada en cada imagen. El planteamiento se basa en la experiencia obtenida en la planeación, ejecución y optimización de proyectos encaminados al rescate del imaginario custodiado por archivos, museos, particulares, instituciones públicas, congregaciones religiosas y centros documentales.

Engloba, en términos generales, todas aquellas pautas indispensables para el manejo formal de contenidos, por lo cual pretende ser tanto una breve fuente de consulta práctica como una medida de fortalecimiento para el control físico, identificación y descripción de la memoria visual del país.

\section{Introducción}

Sujeta a un proceso de evolución, la imagen ha sido plasmada en diversos soportes y técnicas, por lo que su estudio y tratamiento ofrecen un amplio panorama de materiales, condiciones, referencias y contenidos. A través de la fotografía, su legado ha trascendido hasta nuestros días como responsable de un gran impacto cultural que se mantiene como testimonio tangible, guardián de nuestro pasado y fiel reflejo de la sociedad.

Presentes en fondos y colecciones como parte importante del patrimonio documental, se identifican fotografías con elementos tan diversos que implican desde aspectos simples, como la vida cotidiana, hasta obras realmente históricas, poéticas e inclusive artísticas, fuente de información rica y variada.

El acercamiento, caracterización y preservación de los diferentes 
soportes y contenidos representa un continuo desafío para quienes son responsables de su custodia; por lo tanto, la archivística ha incursionado como medio de apoyo fundamental, pues define las vías de acceso más adecuadas y garantiza de forma metodológica la permanencia y conocimiento de la memoria visual a través del manejo de toda la información contenida en cada ejemplar y conjuntos.

\section{Antecedentes}

Los archivos se pueden definir como la suma de tres elementos básicos: documentos, organización y servicio. En este caso, las fotografías son asumidas como elementos testimonio de la memoria colectiva, por lo tanto la imagen y sus contenidos deben interpretarse, pues están presentes en una gran cantidad de archivos, centros documentales, museos e instituciones.

La archivística, ${ }^{1}$ entonces, actúa por medio de una metodología que reúne, conserva y difunde la información con el objetivo de facilitar el manejo de cada ejemplar y conjunto para asegurar su acceso, en cierta medida su permanencia a largo plazo y, en especial, su conocimiento y difusión.

Se ocupa de cada fondo o colección fotográfica útiles para el estudio, investigación, recreación o testimonio, reunida bajo un orden natural como acto voluntario o proporcional a actividades particulares. Es una disciplina que se rige por normas y medidas específicas para el mantenimiento de registros como verdad absoluta, universal, inmutable en el tiempo y extensión de nuestro pasado. ${ }^{2}$

Sin embargo, muchas de las actividades que conlleva la archivística son determinadas en gran medida por otros factores, los cuales generalmente se relacionan con los materiales y procesos fotográficos propios, la disposición y procedencia de sus contenidos, los responsables de su custodia y, en especial, con el presupuesto disponible.

Con la finalidad de establecer una metodología básica para el registro,

1 "La archivística es la ciencia que estudia la naturaleza de los archivos y se ocupa de los principios de conservación y organización de los documentos de archivo y de los medios para su utilización." Heredia, Antonia, Archivística General. Teórica y práctica, p. 159.

2 Casanova, Eugenio, Archivistica, p. 24. 
organización y descripción de ejemplares fotográficos inmersos en fondos o colecciones, las actividades por describirse a continuación únicamente se relacionan con el tratamiento intelectual de fondos o colecciones, por lo cual, la estimación de costos, previsión de recursos, rentabilidad, ente otros temas relacionados, no serán abordados en este artículo.

\section{Etapas}

Ya se pretenda establecer un nuevo procedimiento o continuar con el mismo sistema de trabajo, la gestión y administración de colecciones fotográficas deberá estar orientada siempre a optimizar los resultados. Para dar inicio a todas las actividades, será necesario efectuar su planificación, la cual depende de la determinación de objetivos claros y factibles. Este punto está directamente relacionado con la determinación de la misión y visión tanto de la institución, organismo o responsable de la custodia, como de la colección tratada.

Este planteamiento permite delimitar cada una de las metas, alcances y razones por las cuales se pretende acceder, divulgar y mantener determinada colección. Es independiente de su carácter (institucional, personal, público o privado) e influye directamente en los sistemas de disposición, acceso, consulta e, inclusive, formación y alimentación.

La siguiente etapa corresponde a la planeación del sistema de ingreso, el cual permite reconocer, como medida de control y protección, las referencias básicas de cada ejemplar y su relación con el fondo o colección (ejemplo: procedencia, estado legal, derechos de autor etc.) Para su óptima incorporación, el proceso implica la revisión formal, individual y en conjunto. En esta etapa se recomienda considerar los siguientes campos:

a) Donación: cuando se integran uno o más ejemplares de manera voluntaria y gratuita para su custodia, organización, clasificación, difusión y consulta de manera permanente.

b) Adquisición: cuando el responsable o custodio compra uno o más ejemplares que, por su valor y contenido, directamente se relacionan con la visión y misión de la colección.

c) Comodato: cuando por medio de un convenio se realiza la custodia, organización, clasificación, difusión y consulta de uno o más 
ejemplares por parte del responsable o custodio durante el periodo específico.

d) Préstamo: cuando se estipula la custodia, organización, clasificación, difusión y consulta de uno o más ejemplares por parte del responsable o custodio durante el periodo especificado por la institución cooperativa.

e) Transferencia: cuando se realizan traslados sistemáticos internos que implican la cesión de un ejemplar o colección para su custodia, organización, clasificación, difusión y consulta de manera permanente.

Asimismo, el ingreso involucra el registro de toda la información recomendada en los siguientes campos, los cuales completan las referencias básicas.

a) Número de registro: se aconseja emplear una clave única por cada ejemplar. Esto facilitará su seguimiento. Se pueden usar números y letras.

b) Procedencia: la alimentación de fondos o colecciones puede ser efectuada a través de una o más instituciones, representantes y organismos. Su registro es indispensable para completar el proceso de documentación de forma integral.

c) Tipo de ingreso y fecha: ambos datos deben formar parte de la historia de cada ejemplar; evitando tener que consultar cartas u oficios externos.

d) Tipo de material: ${ }^{3}$ las colecciones fotográficas generalmente están compuestas por imágenes obtenidas a través de diversos procedimientos, por lo que se puede identificar un sinfín de características, formatos y variantes. Por esta razón, deberá ser registrado cada uno de los distintos soportes, para facilitar su procesamiento, incorporación y conservación. Con el fin de abordar brevemente su composición, deben señalarse sus tres elementos constitutivos más importantes:

$3 \mathrm{El}$ proceso de identificación deberá ser apoyado por un especialista; actualmente existen diversos medios auxiliares (http://www.graphicsatlas.org). 
1. Soporte. A largo de la historia han sido empleadas las hojas metálicas, placas de vidrio, papel y polímeros plásticos de acetato o nitrato de celulosa como sustento del resto de los componentes de una fotografía.

2. Aglutinante. Es una sustancia orgánica de origen animal o semi-sintética que recubre el soporte e incluye las sustancias formadoras de la imagen. Su presencia depende del proceso, pues existen imágenes sobre papel que no incluyen esta capa. Aparece en 1850 con el colodión para imágenes negativas sobre vidrio y la albúmina para impresiones en papel. La gelatina apareció hasta 1880, permaneciendo como el aglutinante por excelencia debido a su transparencia, estabilidad y permeabilidad.

3. Sustancias formadoras dela imagen. Dependiendo del proceso, la imagen puede estar compuesta por partículas metálicas de plata, platino, paladio, oro, sales de hierro y colorantes orgánicos. La mayoría de las imágenes de los siglos XIX y Xx están constituidas por depósitos microscópicos de plata metálica, resultantes de la transformación de halogenuros de plata durante la exposición. En el caso de las fotografías a color, los mismos compuestos fotosensibles actúan, pero como precursores de reacciones, ya que permiten la deposición de las sustancias que constituirán la imagen final. 
Tipología DE SOPORTES, EMULSIONES E IMÁGENES FINALES EN FOTOGRAFÍA ${ }^{4}$

\begin{tabular}{|c|c|c|}
\hline Soportes & Emulsiones & Imágenes finales \\
\hline 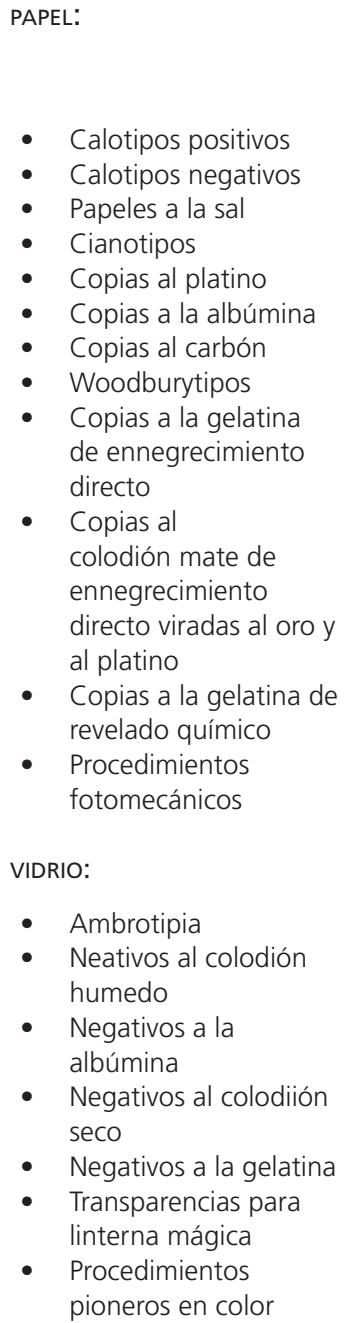 & 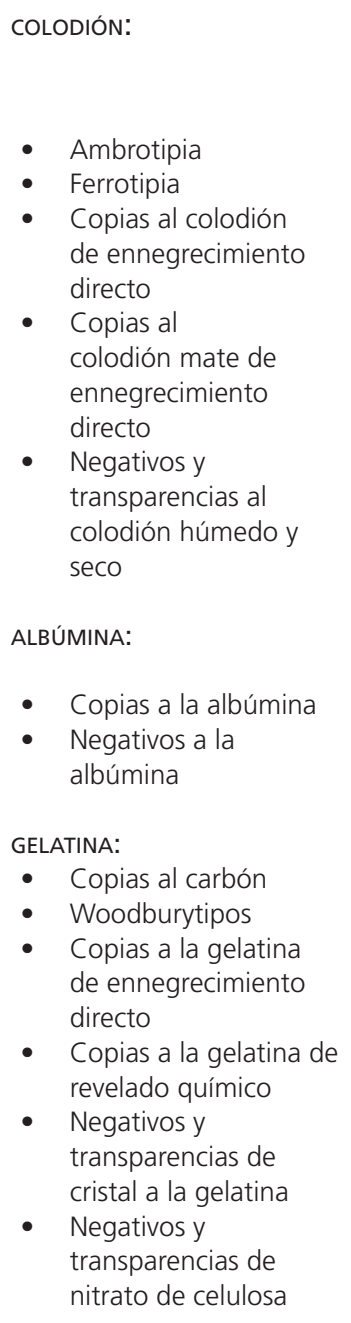 & 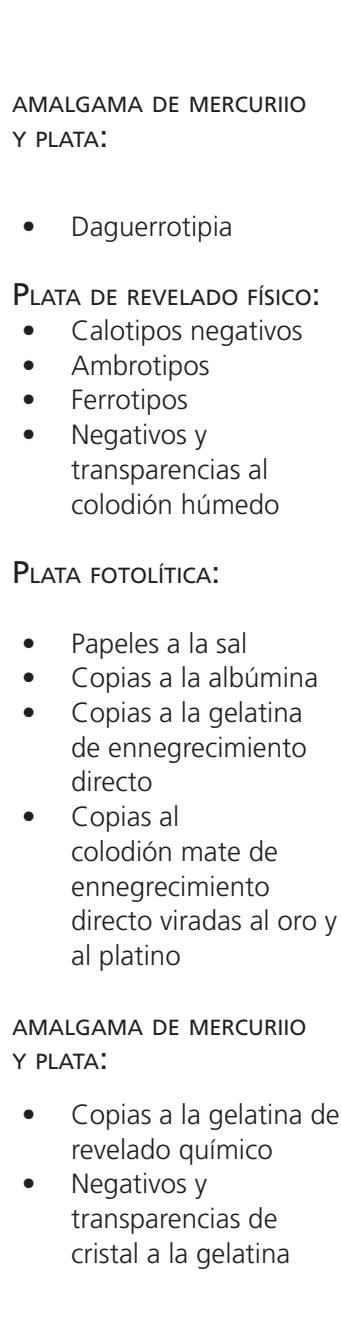 \\
\hline
\end{tabular}

4 Fuentes de Cía, Ángel, La identificación y preservación de los materiales fotográficos, p. 3. 


\begin{tabular}{|c|c|c|}
\hline Soportes & Emulsiones & Imágenes finales \\
\hline $\begin{array}{l}\text { METAL: } \\
\text { - } \quad \text { Daguerrotipia } \\
\text { PLÁstICOS TRANSPARENTES: } \\
\text { - } \quad \text { Nitrato de celulosa } \\
\text { - } \text { Acetato de celulosa } \\
\text { - } \quad \text { Diacetato de celulosa } \\
\text { - } \quad \text { Triacetato de celulosa } \\
\text { - } \quad \text { Poliéster } \\
\text { OTROs: } \\
\text { - } \quad \text { Cerámica } \\
\text { - } \quad \text { Marfil } \\
\text { - } \quad \text { Cuero } \\
\text { - } \quad \text { Piediles }\end{array}$ & 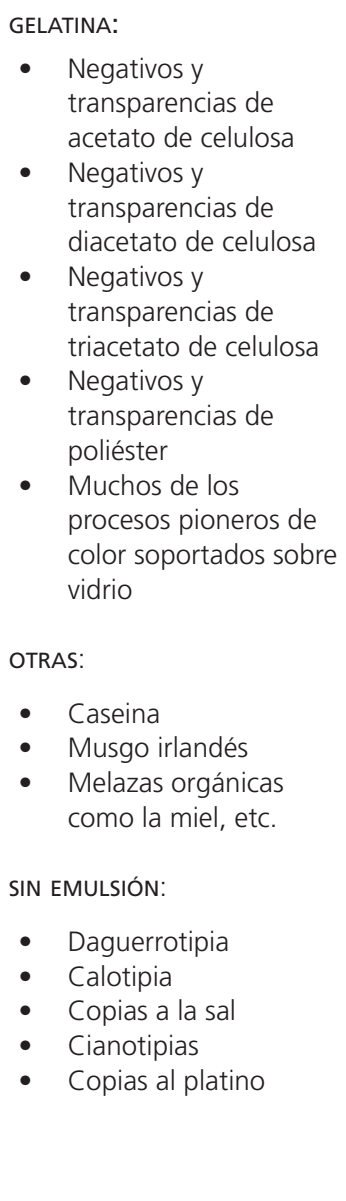 & 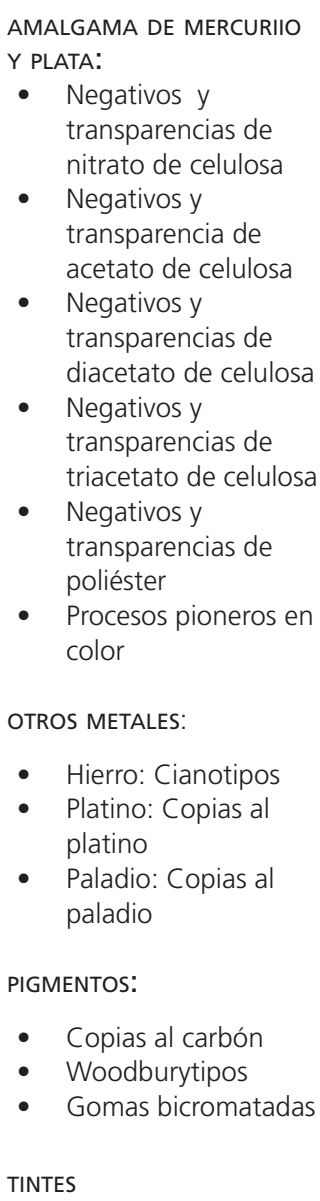 \\
\hline
\end{tabular}


CuAdro de LOS Formatos COMUNES EN EJEMPLARES ANTIGUOS ${ }^{5}$

\begin{tabular}{|c|c|c|}
\hline Doble placa & $21.6 \times 33 \mathrm{~cm}$ & $81 / 2 " \times 13^{\prime \prime}$ \\
\hline Placa entera & $16.5 \times 21.5 \mathrm{~cm}$ & $61 / 2 " \times 81 / 2 "$ \\
\hline Media placa & $11.4 \times 14 \mathrm{~cm}$ & $4 \frac{1}{2}{ }^{\prime \prime} \times 5 \frac{1}{2} 2^{\prime \prime}$ \\
\hline Cuarto de placa & $8.3 \times 10.8 \mathrm{~cm}$ & $31 / 4 " \times 41 / 4 "$ \\
\hline Sexto de placa & $7 \times 8.3 \mathrm{~cm}$ & $23 / 4 " \times 31 / 4 "$ \\
\hline Noveno de placa & $5 \times 6.4 \mathrm{~cm}$ & $2^{\prime \prime} \times 2 \frac{1}{2 \prime \prime}$ \\
\hline
\end{tabular}

CUADRO DE LOS PRINCIPALES FORMATOS CONTEMPORÁNEOS

\begin{tabular}{ll}
\hline $\mathbf{3 5 \mathrm { mm }}$ & $3.2 \times 4.9 \mathrm{~cm}$ \\
$\mathbf{1 2 0}$ & $6 \times 6 \mathrm{~cm}$ \\
$\mathbf{4 \times 5 "}$ & $10.5 \times 13 \mathrm{~cm}$ \\
$\mathbf{4 \times 6 "}$ & $10.5 \times 15.5 \mathrm{~cm}$ \\
$\mathbf{5 x 7 "}$ & $13 \times 18 \mathrm{~cm}$ \\
$\mathbf{8 \times 1 0 "}$ & $21 \times 26 \mathrm{~cm}$ \\
\hline
\end{tabular}

e) Folio. Este campo se refiere a una clave que define, en términos generales, el tipo de ingreso, procedencia y número consecutivo de ingreso para su seguimiento.

Otras líneas de acción medular remiten a los siguientes procesos:

- Selección. Permite distinguir lo trascendental de lo trivial. En el campo de la archivística constituye una participación que requiere la capacidad de identificar el efecto de cada contenido a lo largo de su trayectoria (pasado, presente y futuro). ${ }^{6}$

5 Hernández, "Apuntes de Seminario-Taller de Conservación de materiales fotográficos", ENCRYM, 2005.

6 Nacif, Jorge, Valoración de archivos, p. 10. 
En este punto es importante aclarar que la emisión de un juicio de valor siempre será relativa a un sujeto; sin embargo, tampoco significa que sea una respuesta a un capricho individual, pues consiste en localizar lo importante. Por esta razón, requiere de un conocimiento técnico y profundo para descifrar lo que debe ser conservado y apartar lo irrelevante. Cabe señalar que este proceso también autentifica la documentación a través de criterios formales y materiales; de su resultado, dependen muchas de las medidas para la conservación de la memoria y, por tanto, del patrimonio documental. Por ello, considera a la fotografía como un soporte tangible generalmente ligado a un componente de entorno histórico y transporta una idea, cuyo carácter puede ser informativo o probatorio a múltiples niveles.

- Organización. Corresponde a la distribución de todos los ejemplares en orden alfabético, numérico y cronológico, o bien por asuntos y temas. Al ser un proceso complejo, requiere de un diagnóstico previo para reconocer todos los recursos presentes y llevar a cabo una óptima conformación integral de la colección. El diagnóstico consiste en la evaluación precisa de la estructura, referencias disponibles y ciertos aspectos de conservación de la colección. El análisis, además, considera medios de tránsito, documentación, intervención, consulta y programas de manejo internos para reconocer, de manera formal y jerarquizada, las necesidades específicas y establecer los mejores puntos de acceso.

A este respecto, es importante considerar dos preceptos: el principio de procedencia y el respeto al orden original. ${ }^{7}$ Ambos tienen la finalidad de registrar la trayectoria y mantener el contexto en el proceso de ordenación. Su atención garantiza la conservación integral de la estructura inicial de grupos, series y fondos.

- Descripción. Identifica, puntualiza y establece, en conjunto e individualmente, las características físicas y formales de los

7 Rojas, Leticia, Manual de Archivística de la Administración Pública Federal, p. 19. 


\section{ejemplares fotográficos. Emplea dos herramientas básicas de acceso: el inventario ${ }^{8}$ y la catalogación. ${ }^{9}$}

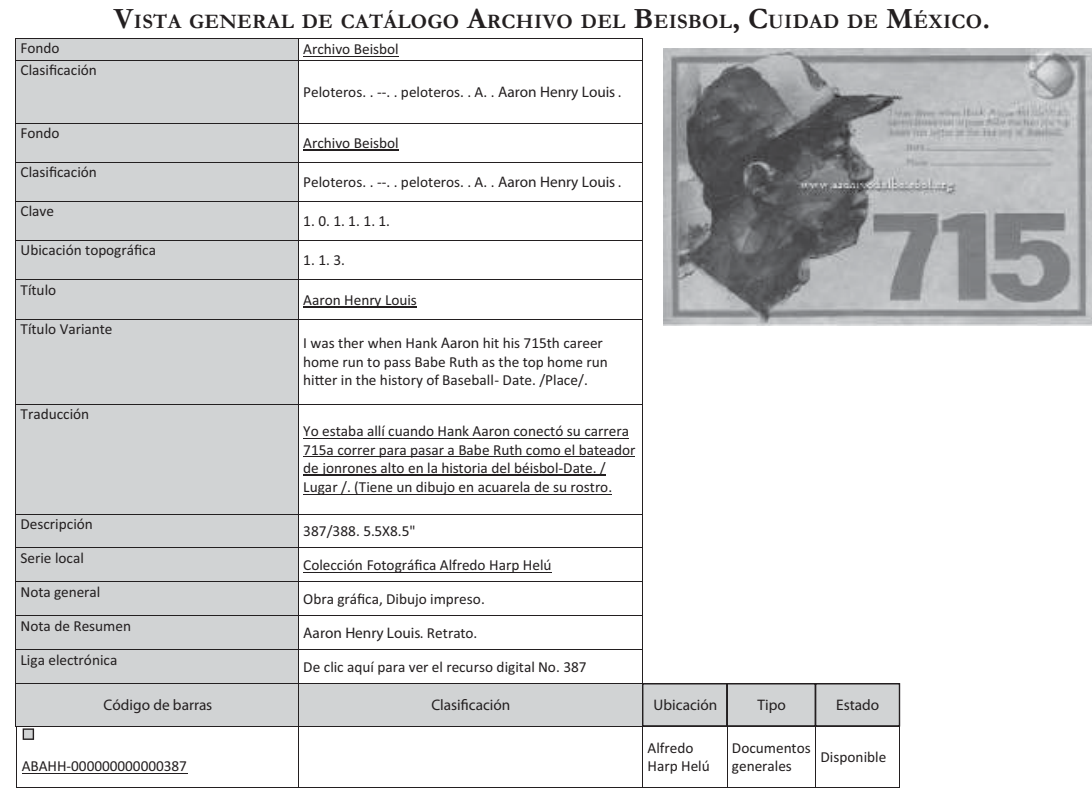

EJEMPLO DE FORMATO DE INVENTARIO

\begin{tabular}{|c|c|c|c|c|c|c|c|c|c|c|c|c|c|c|}
\hline \multicolumn{15}{|c|}{ FONDO } \\
\hline \multirow[b]{2}{*}{ Sección } & \multirow[b]{2}{*}{ Serie } & \multirow{2}{*}{$\begin{array}{l}\text { Núm. } \\
\text { Expediente }\end{array}$} & \multirow{2}{*}{$\begin{array}{l}\text { Nombre } \\
\text { del } \\
\text { Expediente }\end{array}$} & \multicolumn{6}{|c|}{ Fechas extremas } & \multicolumn{3}{|c|}{ Ubicación topogáfica } & \multirow[b]{2}{*}{ Descripcion } & \multirow[b]{2}{*}{ Observaciones } \\
\hline & & & & $\begin{array}{c}\text { Dia } \\
\text { inicial }\end{array}$ & $\begin{array}{c}\text { Dia } \\
\text { final }\end{array}$ & $\begin{array}{l}\text { Mess } \\
\text { inicial }\end{array}$ & $\begin{array}{l}\text { Mes } \\
\text { final }\end{array}$ & $\begin{array}{c}\text { Afio } \\
\text { inicial }\end{array}$ & $\begin{array}{l}\text { Año } \\
\text { final }\end{array}$ & Estante & Charola & Caja & & \\
\hline
\end{tabular}

8 Registro descriptivo que respeta la estructura (contenido) y disposición (ubicación topográfica) de cada conjunto y grupos. En el caso de los archivos fotográficos requiere de campos específicos, tales como: soportes, formatos y procesos. Compila la información precisa de cada fondo o colección, por lo que también incluye tema y fechas extremas para concretar un instrumento de consulta básico.

9 Es el proceso por el cual se identifican y localizan los datos descriptivos y puntos de acceso de cada ejemplar. Se trata de un instrumento intermediario entre el usuario y la colección que se ejecuta conforme a normas establecidas para unificar criterios y globalizar la información. No sólo implica la transcripción de datos, pues permite navegar, seleccionar y obtener referencias precisas, tales como el título, autor y materia. Requiere de un conocimiento técnico y experiencia para recuperación de información. 
Esta etapa permite el procesamiento de la información general y, por ende, facilita el control cuantitativo y cualitativo de la colección en diferentes niveles, por ello se recomienda iniciar el proceso con la revisión preliminar de la colección para definir la línea de sistematización más conveniente de acuerdo con la información disponible.

- Clasificación. Debido a que las colecciones fotográficas son concebidas en su gran mayoría por intereses específicos, este proceso se ejecuta conforme a las referencias y estructura de cada caso, considerando todos los ejemplares — con o sin registro- para realmente crear un reflejo de los contenidos y facilitar el manejo de toda la información.

Se refiere al análisis de datos que permite obtener el mapa organizacional de cada colección en función de los contenidos. Se representa a través de un sistema denominado "cuadro de clasificación", el cual, por medio de categorías, encasilla y jerarquiza la información específica y su relación con el resto de la colección.

El proceso permite establecer las vías de acercamiento más adecuadas para el estudio de la colección, así como reconocer las características físicas, estéticas e históricas de las imágenes a partir del contenido visual e informativo que manifiestan. Es un ejercicio intelectual que debe ser realizado por un especialista, quien establece la calidad visual de cada ejemplar y define la línea de investigación más adecuada. En general se emplean tres categorías principales para organizar los contenidos: fondo, sección y serie, susceptibles de extenderse en subsecciones y subseries conforme a la complejidad y amplitud de cada colección.

- Fondo: conjunto de ejemplares de toda naturaleza reunidos por una persona física o moral, o por una institución, dentro del ejercicio de sus actividades.

- Sección: subdivisión del fondo que conforma una unidad integrada por ejemplares organizados de acuerdo con un contenido específico.

- Subsección: conjunto de ejemplares que forman parte de las secciones, corresponden a las subdivisiones ejecutadas conforme a la complejidad de contenidos. 


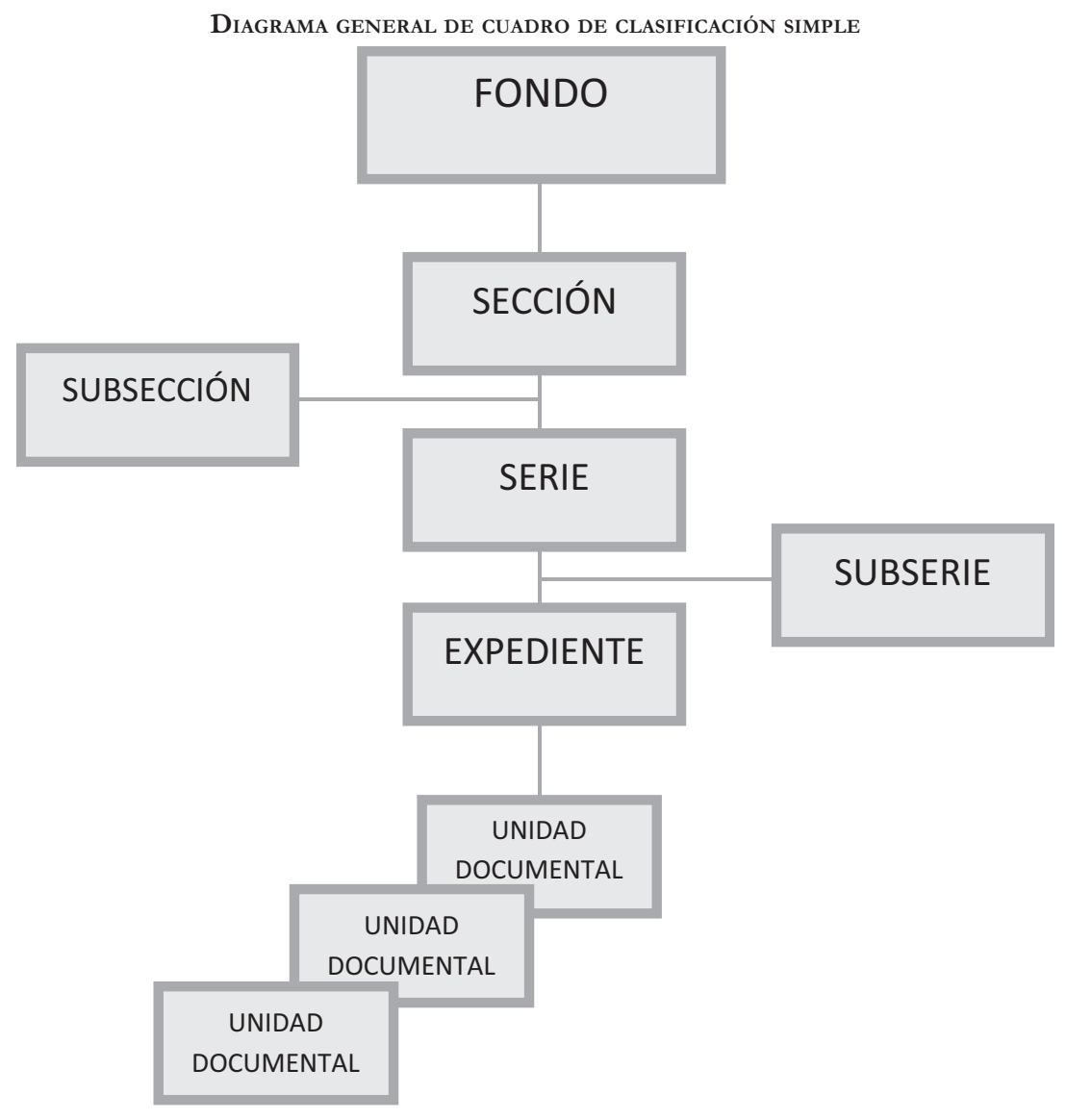

- Serie: conjunto de ejemplares que forman parte de las secciones o subsecciones de un fondo y que se caracterizan por tener elementos semejantes entre sí, basados en el tipo documental.

- Subserie: conjunto de ejemplares que forman parte de una serie, identificadas de forma separada de ésta por su contenido y sus características específicas. 
- Unidad documental: conjunto total de ejemplares relacionados por un mismo tema, asunto o persona.

Existen diversos tipos de cuadros clasificadores, por ejemplo, el alfabético de autores y obras anónimas, el alfabético de título, catálogo de materias y catálogo topográfico ${ }^{10}$ sin embargo, las adaptaciones irán de acuerdo con las características de cada colección, y la estructura del cuadro de clasificación dependerá de su distribución y mejor entendimiento.

- Catalogación. Se puede ejecutar en diferentes niveles, ya que puede involucrar todas las series, es decir, considerando el fondo completo, reconocer el conjunto de unidades documentales, completando entonces las series o aludir a cada ejemplar fotográfico, dependiendo de la información que se quiera recabar.

La eficiencia de este proceso depende del conocimiento de la colección y la investigación realizada, así como de la información misma disponible; además, influye directamente en el servicio a los usuarios, pues identifica el contenido de cada ejemplar para su acceso y difusión de forma homogénea, con el objetivo de intercambiar y poner a disposición la información.

Actualmente existen diversos protocolos establecidos, de los cuales el Marc21 ha sido el más adaptable. ${ }^{11}$ Este formato fue creado para registros bibliográficos y funciona por medio de etiquetas, correspondientes a campos específicos de información. Su estructura ha permitido emplearlo en la descripción de ejemplares fotográficos. A continuación se enlistan las etiquetas más relevantes para la descripción de ejemplares fotográficos:

\begin{tabular}{cc}
\hline Núm. de etiqueta & Referencia \\
\hline 001 & Número de control \\
\hline
\end{tabular}

10 Garrido, Ma. Rosa, Teoría e bistoria de la catalogación de documentos, p. 39.

11 Formato MARC21 conciso para Datos Bibliográficos, Biblioteca del Congreso, Oficina de Desarrollo de Redes y Normas Marc, Edición Concisa de 2007, Actualización núm. 8 (octubre de 2007). 


\begin{tabular}{|c|c|}
\hline Núm. de etiqueta & Referencia \\
\hline 005 & Fecha de ingreso \\
\hline 035 & Número de expediente \\
\hline 090 & Nombre del fondo \\
\hline 091 & Clasificación \\
\hline Subcampo a. & Sección \\
\hline Subcampo b. & Subsección \\
\hline Subcampo c. & Serie \\
\hline Subcampo d. & Subserie \\
\hline Subcampo e. & Expediente \\
\hline 092 & Clasificación \\
\hline Subcampo a. & Colección \\
\hline Subcampo b. & Sección \\
\hline Subcampo c. & Subsección \\
\hline Subcampo d. & Serie \\
\hline Subcampo e. & Subserie \\
\hline Subcampo f. & Expediente \\
\hline 093 & Clasificación Topográfica \\
\hline Subcampo a. & Estante \\
\hline Subcampo b. & Archivero \\
\hline Subcampo c. & Charola \\
\hline Subcampo e. & Caja \\
\hline 100 & $\begin{array}{l}\text { Nombre de autor } \\
\text { (Fotógrafo si presenta) }\end{array}$ \\
\hline 210 & Palabras clave o tema \\
\hline 242 & $\begin{array}{l}\text { Titulo intercalado } \\
\text { (traducción) }\end{array}$ \\
\hline 245 & Titulo \\
\hline 246 & Titulo variante \\
\hline
\end{tabular}

Legajos, número 4, octubre-diciembre, 2014143 


\begin{tabular}{ll}
\hline Núm. de etiqueta & \multicolumn{1}{c}{ Referencia } \\
\hline 247 & Titulo/otro idioma \\
\hline 260 & Publicación \\
\hline Subcampo a. & País \\
\hline Subcampo b. & Estudio o productor \\
\hline Subcampo c. & Cuidad \\
\hline Subcampo e. & Fecha \\
\hline 300 & Descripción física \\
\hline Subcampo a. & Extensión \\
\hline Subcampo b. & Otros detalles \\
\hline Subcampo c. & Dimensiones \\
\hline Subcampo e. & $\begin{array}{l}\text { Materiales } \\
\text { complementarios }\end{array}$ \\
\hline 500 & Tipo de material \\
\hline Subcampo f. & Tamaño de unidad \\
\hline Subcampo g. & Serie/Colección \\
\hline 490 & $\begin{array}{l}\text { Notas de contenido } \\
\text { generales (sellos, firmas } \\
\text { etc.) }\end{array}$ \\
\hline 540 & $\begin{array}{l}\text { Nota de contenido con } \\
\text { formato (contendí de } \\
\text { imagen) }\end{array}$ \\
\hline 500 & Notas de resumen \\
\hline 50 Fuente de adquisición \\
\hline 50 sia
\end{tabular}

Existen otros medios, como la Norma Internacional General de Descripción Archivística, ${ }^{12}$ la cual busca asegurar la creación de descripciones coherentes,

12 Una referencia importante para cualquier actividad de descripción. Ver Lopez, André Porto Ancona, "El contexto archivístico como directriz para la gestión documental de materiales fotográficos de archivo", p. 32. 
facilitar la recuperación y el intercambio de información y posibilitar la integración de otras entidades a un sistema unificado de documentación. Emplea 26 elementos; entre otros, los principales son:
a. El código de referencia
b. El título
c. El productor
d. Las fechas
e. La extensión
f. Nivel de descripción.

En ocasiones, las caracterisitcas de la fotografia demandan una descripcion individualizada que puede generar la pérdida de la globalidad de los fondos y colecciones; sin embargo, la eleccion del sistema de descripcion deberá estar orientada a las políticas internas de descripción de cada entidad.

\section{Metodología}

Los ejemplares fotográficos son materiales que por su naturaleza y composición resultan sumamente susceptibles al deterioro. La conservación tiene el objetivo de mantener y difundir toda la información relevante de carácter técnico, formal, histórico o artístico, valiosa para una sociedad como objeto de estudio.

La conservación proporciona los medios idóneos para adaptar las áreas y sistemas de resguardo, definir los procesos de intervención y restauración más adecuados y prever todas las medidas para evitar daños y solventar emergencias. Sin embargo, su campo de acción no sólo vela por la permanencia física de cada ejemplar, puesto que cada soporte conlleva un contenido. Por esta razón, la archivística es una disciplina ligada a la preservación; de ella depende la generación de una estrategia clara para crear los puntos de acceso y mantener el carácter impalpable de cada ejemplar.

La sistematización de actividades no puede ser mostrada como una receta, pues la diversidad de fondos y colecciones es amplia y muchas veces las fotografías se acompañan de documentos o materiales que involucran otros criterios. Con todo, las líneas de acción son las mismas y el orden de 
ejecución podrá ser modificado de acuerdo con los avances, necesidades y prioridades de cada caso.

El perfil esencial del trabajo siempre será el mismo y tendrá como fin conservar para difundir, difundir para conocer y conocer para generar. Por esta razón, se muestra un cuadro que engloba los fundamentos de este artículo, en espera de que pueda ser empleado para la creación y optimización de proyectos afines.

\section{Conclusión}

La archivística es una ciencia en evolución capaz de adaptarse a la demanda informativa y a la aparición de nuevas tecnologías con el fin de unificar y globalizar contenidos a favor de la trasmisión, enseñanza, manejo y permanencia de la memoria documental.

Su inserción en el área de las colecciones fotográficas exige conocimientos técnicos precisos que permitan la correcta identificación y análisis formal de los diversos procesos técnicos y de la estructura de cada ejemplar.

$\mathrm{Su}$ aplicación requiere del discernimiento integral para el manejo de cada conjunto como parte significativa de la memoria visual del país, por lo que la documentación requiere forzosamente del apoyo de un equipo interdisciplinario.

El desarrollo de una estrategia no sólo deberá estar basado en la experiencia, pues la fotografía está presente en instituciones, museos, archivos, centros documentales y colecciones públicas y privadas, y los métodos para su abordaje dependerán de las políticas de cada entidad para asegurar su acceso y unificar criterios.

Se recomienda publicar los resultados para estimular la investigación e intercambio de información, y favorecer la construcción de una memoria colectiva. Es prioritario robustecer la influencia de la archivística aplicada al imaginario nacional, por ello este artículo intenta retomar los conceptos fundamentales y ofrecer al lector tanto un panorama del presente, así como los instrumentos necesarios básicos para articular un tratamiento inicial.

El propósito es contribuir a incentivar la formación de quienes prestan su servicio al material fotográfico y aspiran a desarrollar su labor profesional en este campo. 
CuAdro gENERAL DE LAS ETAPAS PRINCIPALES PARA LA DOCUMENTACIÓN DE COLECCIONES FOTOGRÁFICAS

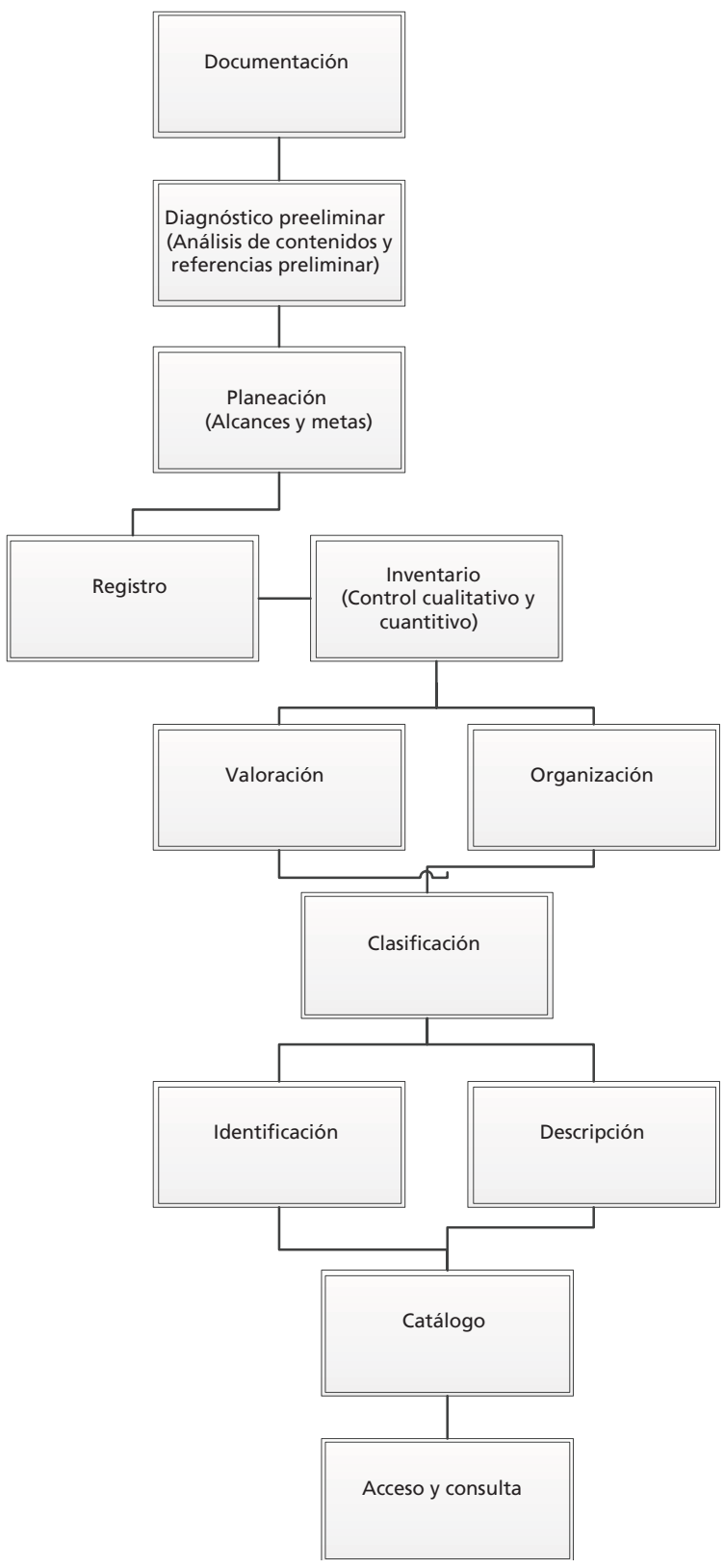

Legajos, número 4, octubre-diciembre, 2014147 


\section{Bibliografía básica}

Boadas, Joan, Manual para la gestión de fondos y colecciones fotográficas, Girona, CCG Ediciones Ajuntament de Girona (CRDI), 2001.

Heredia, Antonia, Archivística General. Teoría y práctica, Sevilla, Graficas del Sur, 1991.

Nacif, Jorge, Valoración de Archivos, México, Archivo General de la Nación, 2002.

Rojas, Leticia, Manual de Archivística de la Administración Pública Federal, Apoyo al Desarrollo de Archivos y Bibliotecas de México A. C, 2010.

\section{Fuentes consultadas en la web}

Astudillo, Cecilia, Manual de procedimiento para la catalogación de documentos patrimoniales bistóricos y etnográficos, Manual técnico 2. Red de archivos patrimoniales, Sistema de Biblioteca Pontificia Universidad Católica de Valparaiso, Chile, 2010 disponible para su consulta en http://margotloyola. ucv.cl/wp-content/uploads/2010/03/Manual_de_catalogacion_de_ documentos_historicos_y_etnograficos.pdf

Biblioteca del Congreso, Formato MARC21 conciso para Datos Bibliográficos, Oficina de Desarrollo de Redes y Normas Marc, Edición Concisa de 2007, consultado en Actualización Núm. 8 (Octubre de 2007). http://www.loc. gov/marc/bibliographic/ecbdspa.html

Casanova, Eugenio, Archivística, Siena, Stab Arti Grafiche Lazzeri, 1928, consultado en http://www.icar.beniculturali.it/biblio/pdf/EuCa/ totalCasanova.pdf

Fuentes de Cía, Ángel, "La identificación y preservación de los materiales fotográficos", en La identificación y preservación de los materiales fotográficos, consultado en http://www.angelfuentes.es/PDF/Identificacion_ preservacion.pdf

Garrido, María Rosa, Teoría e historia de la catalogación de documentos. Cap. 2, 
consultado en http://infocuib.laborales.unam.mx/ ec08s02b/archivos/ data/1/23.pdf

Gobierno de España, Manuales de Archivisitca, Ministerio de educación, cultura y deporte, disponible en http://www.mecd.gob.es/cultura-mecd/ areas-cultura/archivos/recursos-profesionales/manuales-de-archivistica. html

Ancona Lopez, André Porto, "El contexto archivístico como directriz para la gestión documental de materiales fotográficos de archivo", en Universum. Revista de Humanidades y Ciencias Sociales, vol. 2, núm. 23, 2008, pp. 12-37, Universidad de Talca, Talca, Chile.

Serie de IFLA sobre control bibliográfico, Principios para la catalogación de IFLA: Pasos hacia un código internacional de catalogación, v. 26, Frankfurt, Ministerio de Cultura, 2003, disponible en http:/ /www.ifla.org/files/assets/cataloguing/ icc/ime-icc-1-es.pdf 